\title{
EL LIBRETO DE ÓPERA EN ESPAÑA COMO FUENTE PARA EL ESTUDIO DE LA PRÁCTICA MUSICAL: LOS LIBRETOS ESPAÑOLES DE LA PRIMERA MITAD DEL SIGLO XIX
}

\author{
OPERA LIBRETTI IN SPAIN AS A SOURCE FOR THE STUDY OF \\ PERFORMANCE PRACTICE: SPANISH LIBRETTI FROM THE FIRST \\ HALF OF $19^{\text {TH }}$ CENTURY
}

Marc Heilbron Ferrer

Escola Superior de Música de Catalunya (ESMuC)

\begin{abstract}
Resumen:
Los libretos que se publicaban con motivo de las representaciones de una ópera en la primera mitad del siglo XIX no han merecido mucha consideración como fuentes documentales para la investigación del teatro musical. La modestia de la mayoría de las ediciones -se trataba de un tipo de publicación de uso práctico y de formato reducido- puede haber contribuido a su infravaloración. A partir de ejemplos de libretos publicados en España en la primera mitad del siglo XIX, se señalan casos en los que el libreto permite documentar prácticas interpretativas en paralelo a las que pueden aportan otro tipo de fuentes musicales.
\end{abstract}

Palabras clave:

Libreto, ópera, representación, interpretación, aria, cantante.

Abstract:

The libretti that are published on the occasion of the performances of an opera in the first half of the nineteenth century have not received much consideration as documentary sources for the investigation of musical theater. The modesty of most editions-it was a kind of practical use and publication of small form-may have contributed to its underestimation. From examples of libretti published in Spain in the first half of the nineteenth century, the paper identifies cases where the libretto allows performance practices that may contribute to other music sources.

Keywords:

Libretto, opera, performance practice, aria, singer. 
El objeto de estudio de este artículo es un tipo de edición concreta de libreto de ópera: la que se publicaba con motivo de la representación de la ópera y que cumplía funciones similares a lo que posteriormente se llamó "programa de mano". Este tipo de libreto, nacido con las primeras representaciones de ópera en el siglo XVII, recogía el texto de la representación tal como se interpretaba en un determinado teatro con variaciones en ocasiones muy notables entre diversas ediciones y cuyo origen en la mayoría de los casos hay que asociar a la práctica habitual de los cantantes de añadir, suprimir o interpolar arias provenientes de otras óperas o escritas expresamente para ellos por un compositor ${ }^{1}$.

En las últimas décadas del siglo XIX, el libreto dejó de editarse de forma asociada a una representación. El nuevo "programa de mano" con el reparto de intérpretes y un breve resumen argumental substituyó al libreto que empezó a ser publicado por los editores de la música o bien editores autorizados de forma independiente. Los motivos del cambio fueron diversos: además de la cuestión de los derechos de autor, es evidente que se estabilizó un canon, que cada vez incluía más reposiciones de óperas del pasado en las que paulatinamente fue disminuyendo (aunque no desapareciendo del todo) la práctica de interpolar arias o escenas de otras óperas.

Respecto al tipo de edición de los antiguos libretos resulta difícil establecer un "modelo" puesto que cambia mucho en función del lugar y la época pero la descripción de diversos ejemplos extraídos de diferentes libretos editados en España en el siglo XIX puede resultar útil como propuesta para el análisis de este tipo de fuentes.
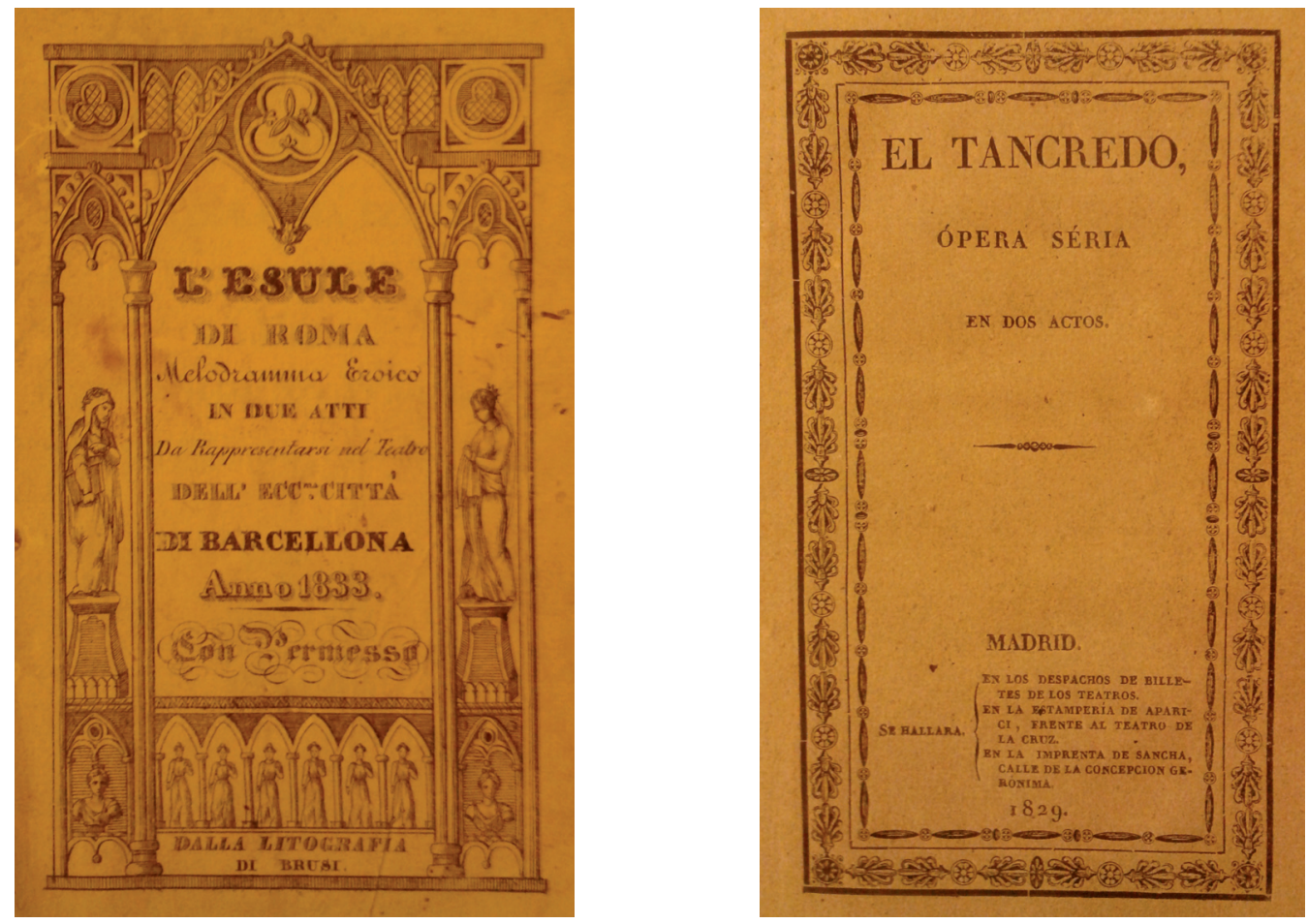

1 Sobre arias añadidas cfr. PORISS, 2009. 
Es interesante señalar que si bien en España la mayoría de las portadas están escritas en lengua castellana, ciudades como Barcelona tal como puede verse en el ejemplo de L'esule di Roma (Fig.1), publicaban la portada en italiano, italianizando incluso el nombre de la ciudad. Esta característica se asocia a los estrechos contactos comerciales y culturales que unían la ciudad con Italia. De hecho, Barcelona era casi una "plaza" más del mercado de ópera italiana de finales del siglo XVIII y principios del siglo XIX, que contaba además con una considerable colonia de italianos afincados en ella. En este contexto vale la pena señalar la presencia en las carteleras de obras teatrales en italiano representadas por compañías extranjeras a partir de 1845. Tanto en el Teatro de la Santa Cruz como después en el Liceo actuaron algunos de los actores de prosa italianos más famosos de su tiempo como Adelaide Ristori y Ernesto Rossi ${ }^{2}$. Por contra, en el libreto del Tancredi madrileño, aunque en el interior aparece el texto italiano junto a su traducción predomina la castellanización de todos los elementos, quizás como herencia de aquel período durante los últimos años del reinado de Carlos IV en los que fueron prohibidas las representaciones de ópera en lengua extranjera. Años después en los libretos del Teatro Real llegó a desaparecer el libreto italiano y se publicaba únicamente la traducción castellana pese a representarse la ópera en italiano ${ }^{3}$.

La portada interior de este tipo de ediciones o bien repite la información de la cubierta o amplia algo más la información de la misma. Siguiendo la tradición italiana que por lo menos nominalmente daba una mayor importancia al autor del texto del libreto es muy habitual también encontrar el nombre del libretista antes que el del compositor.

Las óperas francesas, como Le comte Ory $y^{4}$ era representadas en italiano. La práctica habitual de la época era representar las óperas en italiano, aunque hubiesen sido escritas originalmente en francés y aún siendo Francia geográficamente y, en algunos aspectos, culturalmente muy próxima. La representación de obras en lengua francesa durante el siglo XIX se circunscribió a circunstancias políticas determinadas como fue el breve reinado de José I Bonaparte en el que fueron representadas opérascomiques de autores como Dalayrac o Boildieu. Este tipo de espectáculos (por otra parte frecuentes en la mayoría de los territorios europeos conquistados militarmente por Napoleón) no arraigaron en España y hasta principios del siglo XX las óperas francesas y alemanas se interpretaron sistemáticamente en lengua italiana.

El título mismo que se le da a la ópera representada puede prestarse a confusión, especialmente en los casos en que existen diferentes versiones de una misma ópera. Así ocurre, por ejemplo con el Mosè de Rossini: Una primera versión Mosè in Egitto, fue estrenada por Rossini en Nápoles en 1818 y una segunda versión se estrenó en París bajo el título Moïse et Pharaon (1827), en lengua francesa, con cambios en los nombres de algunos personajes y notables diferencias en la partitura.

2 BOHIGAS TARRAGÓ, 1946.

3 El trovador, 1854.

4 Il conte Ory, 1830 
De esta segunda versión se realizó a su vez una traducción al italiano que con el título Mosè era la que habitualmente se representaba en España, aunque con diferentes títulos: En Valencia, por ejemplo, se representó en 1842 todavía con el título de la primera versión Moisés en Egipto. La misma versión se representó en Barcelona en 1859 con un título más clarificador pero del todo inusual hoy: Il nuovo Mosè. Puesto que la portada resulta aquí confusa y en muchos casos los materiales de la orquesta han desaparecido sólo el estudio de los libretos puede determinar cual de las versiones fue la efectivamente se representó.

\section{EL REPARTO Y LA ORQUESTA}

Los libretos incluyen en la segunda o en la tercera página el reparto de la obra. Los personajes de la obra son descritos habitualmente estableciendo el tipo de relación que hay entre ellos tal como ocurre en el teatro en prosa "padre de" "confidente de...", así como una función social que desempeñan "rey de Lesbos", "general de Mitiline"5 etc. Junto al nombre de cada uno de los personajes aparece siempre el del intérprete. La presencia del nombre de los cantantes es esencial para establecer la circulación de cantantes y de la música en toda Europa. Estos repartos recogidos en los libretos fueron la fuente principal que en su día sirvió a autores como Emilio Cotarelo y Mori o Luis Carmena y Millán para la publicación de sus trabajos pioneros en España sobre la historia de la ópera en nuestro país. En los libretos españoles no es demasiado habitual la práctica frecuente en Italia de incluir el rango del cantante "prima donna", "primo tenore" o alguno de los títulos que el cantante quisiera dar a conocer al público: "academico filarmonico de Bolonia", "cantante de cámara de S.M." etc. Además del reparto de cantantes no se obvia el papel que representará el coro "caballeros siracusanos, doncellas, guerreros y escuderos" ${ }^{\text {y }}$ la presencia de determinados comparsas que no cantan aunque aparecen claramente diferenciados en la escena como por ejemplo "un notario", aunque este tipo de papeles confiados a comparsas no incluyen el nombre del intérprete.

Resulta sorprendente que el italianismo predominante en los libretos barceloneses tenga un capítulo más en la aparición de los nombres de pila e incluso de algunos apellidos en su versión italianizada.

5 Zelmira, 1826: 5

6 El Tancredo, 1829: 5 
Por debajo del reparto, se especifica el lugar y tiempo de la escena. En algún caso, como en el de La traviata este detalle confirma la práctica decimonónica de representar esta ópera ambientada en el siglo XVIII ${ }^{7}$ por motivos de censura, tal como le ocurrió a Verdi en el estreno de la ópera.

Particularmente interesante es la referencia al "director" de la representación. Es sabido que la función del director de orquesta no tenía la misma consideración profesional y artística a principios del siglo XIX que en la actualidad. Los sustantivos que acompañan este nombre pueden en algunos casos dar una pista sobre la función que desempeñaban. Así por ejemplo, Ramón Carnicer aparece como "Maestro director al piano" de la representación de Blanca de Messina de Vaccai ${ }^{8}$ que tuvo lugar en Madrid en 1832 mientras tres años antes aparece como "Maestro, compositor y director" en la representación de Tancredi ya mencionada. Muy probablemente, Carnicer acompañaba los recitativos en el primer en caso, y probablemente también en el segundo, puesto que no se especifica la existencia de otro maestro. La alusión a su labor como "compositor" hace posible pensar que algunos arreglos específicamente realizados para aquella representación provenían de su propia mano. El compositor Saverio Mercadante en las representaciones de su propia ópera Elisa e Claudio representada en Madrid en 1826 aparece únicamente como director: "La música es del célebre maestro Don Saverio Mercadante, director de esta compañía italiana. Otro maestro al piano Don Estevan Moreno"10

Resulta evidente que los mismos sustantivos se utilizaban para describir funciones diferentes en Barcelona. Así por ejemplo, en la primera representación de la ópera Linda di Chamounix en Españase cita "Maestro al cembalo Signor Matteo Ferrer"11 con grandes caracteres mientras que más secundariamente aparece Michele Angelo Rachel como "Primo violino e direttore dell'orchestra". Muchos libretos barceloneses incluyen también los nombres de los principales miembros de la orquesta. Véase la figura 3 en la que aparece este listado -con todos los nombres de los músicos italianizados- en esta representación de Linda di Chamounix. Es interesante señalar por ejemplo que a partir de la información aportada por el libreto sabemos que durante esas representaciones el continuo en los recitativos de la ópera no era interpretado únicamente con el cembalo sino también por el violonchelo. La práctica de incorporar algún otro instrumento al bajo es cada vez más habitual en las representaciones modernas pero todavía hoy hay directores que inexplicablemente realizan el acompañamiento solo con el clave o el fortepiano.

El hecho de que en algunas representaciones aparezcan también los nombres de los principales miembros de la orquesta puede aportar algún tipo de información suplementaria para conocer la trayectoria de determinados músicos de cierta relevancia en la vida musical de la época como es el caso de

7 La Traviata, 1855: 4.

8 Bianca di Messina., 1832: 3

9 Tancredo, 1829: 5

10 Elisa y Claudio. 1826: 2.

11 Linda di Chamounix. 1844: IV. 
músicos de prestigio como Ramón Vilanova "Aditto facoltativo del reale Conservatorio di Maria Cristina, membro della società del fomento dell'illustrazione, e direttore di musica del Instituto Barcellonese”.

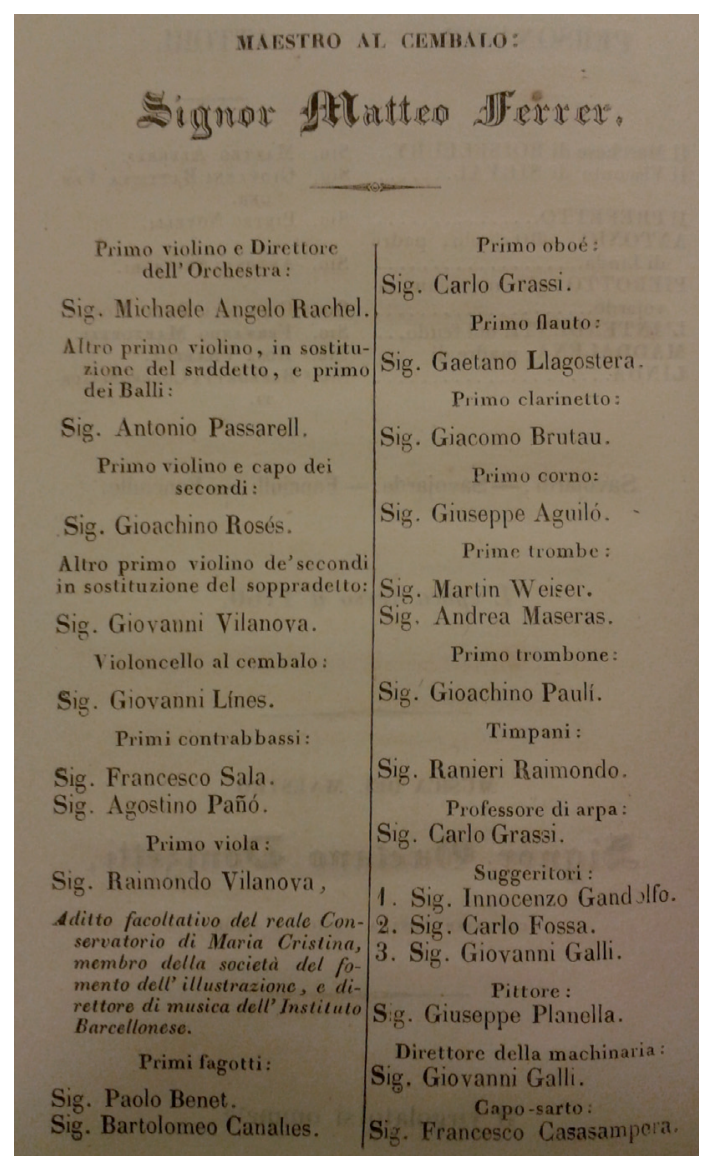

En esta sección pueden aparecer los nombres de otros responsables de la escena. Aparecen citados en ocasiones el apuntador o los diversos apuntadores "Suggeritori. $1^{\circ} \mathrm{Sig}$. Innocenzo Gandolfo, $2^{\circ}$ Sig. Carlo Fossa, $3^{\circ}$ Sig. Giovanni Gali" 12 . Es evidente que la práctica musical actual y la de la época difieren en el número de apuntadores. Hoy en día no hay más que un sólo apuntador e incluso algunos teatros prescinden de esta figura. La función que estos apuntadores debían tener, además de ser la que habitualmente se atribuye al apuntador, debía incluir funciones que actualmente desarrollan lo que actualmente se conoce como regidores de escena. Es probable que un apuntador se situase en la concha mientras los otros dos se situaban a cada uno de los lados del escenario. Esta situación de apuntadores entre bastidores sería la que haría posible que el apuntador desempeñase también funciones de director de la banda interna tal como ocurría en el Teatro Principal de Valencia: "Primer Apuntador y Director de la Banda D.

12 Linda di Chamounix. 1844: IV 
Teodoro Bueno"13. Puede aparecer también, aunque no siempre, el nombre los autores de la escenografía o citar incluso al responsable o responsables del vestuario. Un caso excepcional es el de algunos libretos valencianos que citan incluso el término "Director de escena" ${ }^{14}$ y que muestra que al menos en aquellas representaciones había un responsable específico encargado del movimiento escénico. En el caso de incluir escenas de baile o bailes interpolados entre un acto y otro también aparecen los responsables de la coreografía y los bailarines principales. Así ocurre por ejemplo en el libreto de Los mártires de Donizetti en el que aparece el nombre de las principales bailarinas "esclavas - amazonas" y se indica además la presencia de "Figurantas 32" que componían el resto del cuerpo de baile.

La sinopsis argumental del libreto que aparece en muchos de ellos resulta particularmente interesante para analizar la recepción de la ópera especialmente cuando se refiere a temáticas conflictivas. Impagable la explicación argumental de La traviata en su representación en el Teatro Principal de Barcelona:

"Resumen del argumento.

Una mujer que se descarrió (1), que se separó del recto camino de la virtud y se entregó á toda clase de desórdenes para seguir ciegamente sus pasiones, llega por fin á convencerse de que la Religion solamente es la que puede consolar y satisfacer nuestro corazón. La causa primera de este cambio es sin duda el verdadero amor del joven Alfredo, que pudo por fin arrancar á Violetta de su encenegamiento.

(1) El que por debilidad ó por error no sigue la verdadera senda, se extravía; mal el que voluntariamente se aparta de lo justo y razonable sabiendo que hace mal, se descarría"15

En óperas como Maria Stuarda con un trasfondo de conflicto religioso y que representaban la muerte de un monarca en escena se describe a Maria como "abandonada a un parlamento [inglés] fanático y servil, que creía poder hacer un servicio a su religión sacrificándole una reina católica"16.

La recepción de un argumento que alude a la imaginaria reina Caritea de España no debió agradar a la censura a juzgar por la advertencia que precede al argumento del libreto de estreno de la ópera Caritea regina di Spagna de Mercadante:

"El argumento de esta ópera, está tomado de una tragedia italiana y de esta suerte se va repitiendo un hecho fabuloso cuyos personages y nombres que se les dan no existieron jamas y son desconocidos para los españoles. Sería de desear que este egemplo no se repitiese, pues pudiera suceder que no estando todos en posición de distinguir lo cierto de lo fabuloso, el poner en escena asuntos apócrifos con el carácter de históricos, contribuyese á propagar errores en vez de instruir, que es el objeto del teatro"17

13 Moisés en Egipto. 1842: 4.

14 Moisés en Egipto, 1842: 4.

15 La Traviata, 1855: 5

16 Maria Stuarda, 1843: 6

17 Caritea Reina de España 1830: 3 
Algunos libretos incluyen también el número de músicos de la orquesta lo cual contribuye a dar una información más sobre el carácter de las orquestas y el número de músicos que actuaban en una determinada representación. En algunos casos se menciona la presencia de "60 profesores"18 quizás porque en aquellos años el Liceu rivalizaba con el Teatro Principal en Barcelona.

\section{EL LIBRETO: EL TEXTO Y SU TRADUCCIÓN}

Algunos libretos incluyen al final del reparto una nota breve en pequeños caracteres pero de gran importancia para analizar los elementos relacionados con la representación. "Lo anotado entre comillas se omite" 19 . Esta nota se refiere a las comillas que aparecen a lo largo del texto del libreto publicado y permiten saber que escenas o fragmentos, a veces muy breves, se eliminaron de la representación. En la mayoría de los casos, sin embargo, el texto se eliminaba sin indicación alguna por lo es necesario confrontarlo con otros libretos para descubrir los frecuentes cortes o intentar localizar los orígenes en algunos cambios.

Un caso emblemático es el de las representaciones de óperas como Don Giovanni de Mozart. Es sabido que el Don Giovanni fue la ópera de Mozart que más se representó en el siglo XIX puesto que algunas de sus características como los elementos fantásticos de la obra y el carácter del personaje encajaban mejor con la dramaturgia romántica que otro tipo de temas mozartianos. Sin embargo, la intención de “ajustar" la trama de la obra a la concepción romántica del siglo XIX hacía inconcebible que existiese una escena después de la muerte del protagonista conducido a los infiernos. Esta escena, en la que los principales personajes (excepto Don Giovanni) cantan lo que podemos considerar una "moraleja" era cortada sistemáticamente y no aparece en los libretos de las representaciones del siglo XIX ${ }^{20}$.

Algunos textos eliminados nos dan pautas para reconocer pasajes eliminados que son particularmente significativos desde el punto de vista musical. Sirvan como ejemplo la supresión de la segunda estrofa de "A te o cara" en la que Arturo alcanza el do\# y que no aparece en la representación valenciana de $I$ Puritani ${ }^{21}$ que cantaba el tenor Eugenio Hordan ${ }^{22}$. o la eliminación total de "D'amor sull'ali rosee", en la en el ya mencionado libreto de El trovador en Madrid que pasa directamente del recitativo al "Miserere" y la cabaletta del aria. El papel de Leonora lo cantó la soprano Marietta Gazzaniga Malaspina, que pese a haber estrenado óperas de Verdi como Luisa Miller o Stiffelio es evidente que prefirió suprimir esta parte en la primera representación de Il trovatore en Madrid.

El libreto incluía también el texto de las arias o dúos añadidos o de substitución por los principales cantantes de aquella representación. Es sabido que a lo largo del siglo XVIII y hasta mediados del siglo

18 Paulina y Poliuto o Los Mártires, 1849: 8

19 Paulina y Poliuto o Los Mártires, 1849: 3

20 Juan Tenorio o El disoluto castigado. 1866.

21 I Puritani, 1845: 24

22 El detalle pone un poco en entredicho los elogios a veces desmesurados con los que eran tratados los cantantes en la literatura posterior: véase Antonio de Gordon y de Acosta: Consideraciones sobre la voz humana, La Habana, Imprenta Militar, 1899., p. 32. en los que se comparan los sobreagudos de Eugenio Hordan a los de Enrico Tamberlick o Julián Gayarre. 
XIX era habitual que los cantantes eliminasen algunas de las arias de la representación e incluyesen arias provenientes de otras óperas o escritas incluso específicamente para la ocasión por otro compositor. Un caso conocido en España es el de Ramón Carnicer al frente del Teatro de la Santa Cruz en Barcelona y de los teatros de la Cruz y del Príncipe en Madrid que compuso algunas arias para ser insertadas en óperas de otros compositores ${ }^{23}$.

Un ejemplo de un dúo retomado de otra ópera lo encontramos en el libreto de La sonnambula madrileña de 1834. El tenor Giovanni Battista Genero y la soprano Giuditta Grisi cantaron "Quella rammenta serena autora", dúo perteneciente a la ópera il Talismano de Giovanni Pacini ${ }^{24}$.

En este apartado podrían incluirse los cambios en la primera representación en Barcelona de L'Elisir d'amore de Donizetti en la que Pasqualotto (nombre utilizado en el libreto en vez del de Nemorino) substituye "Una furtiva lagrima" por un texto bastante similar cuya métrica denota que no se trataba de la música de la famosa y que más bien parece un recitativo 25 :

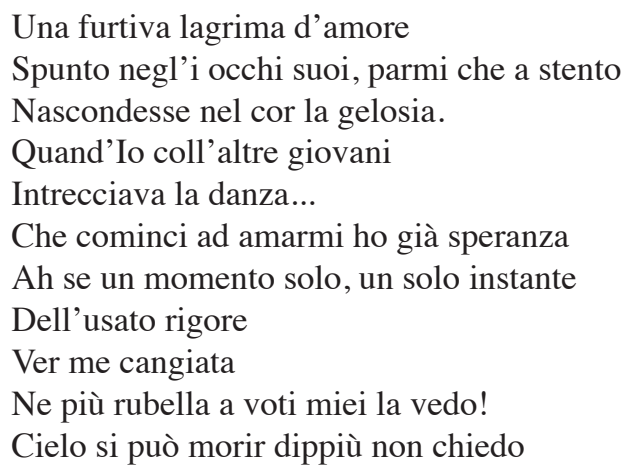

El libreto de L'elisir d'amore de Barcelona no está traducido al castellano como si lo está el de Madrid, donde ese mismo año también se representó L'elisir d'amore de forma más fiel que en Barcelona, incluyendo el texto íntegro de "Una furtiva lagrima" ${ }^{26}$. El libreto de la representación madrileña apenas presenta cambios significativos pero alguna omisión en la traducción parece no ser casual: En el aria de Dulcamara se omite la traducción de los versos "Voi giovani galanti per sempre avere amanti", una forma de discreta censura, que sin duda no es casual.

Vale la pena detenerse de forma pormenorizada en la revisión del texto de un libreto de la época de Ramon Carnicer para entender hasta que punto el libreto revela los cambios a los que una ópera habitual en la época como Tancredi podía cambiar.

23 PAGAN / DE VICENTE, 1997: 345-391

24 La Sonambula, 1834: 24.

25 Sobre la estructura métrica de las arias de ópera italiana, Cfr. BIANCONI, 2005: 183-218. FABBRI, 2007 : $18-28$.

26 Sobre un análisis de la traducción métrica al castellano de algunos versos de L'Elisir d'amore, Cfr: SUBIRÁ, 1973 : 121 


\section{UNA REPRESENTACIÓN DE TANCREDI EN MADRID}

Tal como ya hemos visto Tancredi fue representada en Madrid en 1829. La ópera fue interpretada, además de por el ya mencionado, Francisco Piermarini (Argirio), por Concepción Lledó (Amenaida), Brigida Lorenzani (Tancredo), Juan Giordani (Orbazano), Clementina Lang (Isaura) y Pedro Mantegazza (Rogiero) bajo la dirección de Ramón Carnicer.

El principio del libreto publicado por la Imprenta de Sancha no revela apenas ningún cambio significativo en las primeras escenas de la ópera, incluyendo la famosa cavatina "Di tanti palpiti". El primer cambio importante lo encontramos en la primera aria de Argirio (Francesco Piermarini). El aria original "Pensa che sei mia figlia" fue substituida por Piermarini por otra aria titulada "Soffrir non vo' l'ofessa". De hecho es toda la escena la que cambia puesto que tampoco la cabaletta del aria es la misma. Puede que se trate de un aria escrita específicamente para ser insertada en esta ópera, es posible que por el propio Francesco Piermarini, que también era compositor o por Ramón Carnicer ${ }^{27}$.

Otro cambio consiste en la supresión de una buena parte del recitativo que precede a la escena final del acto. Concretamente el texto suprimido es el recitativo en el que Amenaide intenta revelarse contra la voluntad de su padre: desde "T’arresta" hasta enlazar con la última frase "Oh padre".

La coincidencia es total en escena final del acto I, una finale concertante típico de la época que es lógico que no presente cambios puesto que dramáticamente siendo al ser una escena de conjunto no está pensada para la exhibición vocal de cada uno de los solistas tal como ocurre con las arias o los dúos.

El recitativo con el que empieza el acto II también fue suprimido en la representación madrileña que empezó con una escena cantada por Isaura y el coro que no pertenece Tancredi: "Di quell'indegna". Tampoco la escena que sigue, con Orbazzano como protagonista, interpretando el aria "Sento diviso il core" pertenece a Tancredi. Este aria sustituye a la que en la ópera original cantaba el tenor (Argirio) "Ah segnar invano io tento". Los cambios prosiguen todavía en las siguientes escenas en la que se suprime el aria del sorbetto "Tu che i miseri conforti" que canta Isaura, que avanzado el acto interpretará otra aria "Era felice un dì" no identificada. Tampoco cantó en Madrid Amenaide su aria "No che il morir non è". Así pues no hay ningún punto en contacto entre la representación madrileña y el original rossiniano hasta el recitativo de la escena V del libreto original "Di già l'ora" a partir del cual encontramos el dúo de Argirio y Tancredi tal como aparece en el original lo mismo que la segunda aria de Amenaide "Giusto Dio che umile adoro". Suprimieron también un breve recitativo de Isaura antes del coro "Plaudite" y después del coro se encuentra el aria "Era un felice dì" de Isaura que ya hemos mencionado. De hecho el segundo acto en Madrid fue más breve que el original porque se suprimió el dúo entre Tancredi y Amenaide y el recitativo y el aria de Roggiero. El final de la obra tiene otro corte en el coro "Solamir d'Amenaide" A partir de ahí y hasta el final el libreto recoge el texto original del estreno veneciano.

27 PAGAN / DE VICENTE, 1997: 387-388. Citan la existencia de un duetto entre Argirio y Orbazzano que no aparece en el libreto de la representación de 1829 y que quizás fue interpretado durante esta representación. "Eccomi o cavalieri...Deh lasciate". 
El ejemplo de Tancredi ilustra muy bien la cantidad de cambios, supresiones de escenas, arias y dúos añadidos que se podía hacer en una representación de ópera a principios del siglo XIX. Aunque la existencia de este tipo de cambios ha sido considerado como una muestra de los excesos permitidos a los cantantes, una visión más amplia, podría valorarlos como una práctica normal en una época que consideraba el concepto de obra en un sentido más abierto. De hecho, casi podría afirmarse que a la luz del testimonio que ofrecen los libretos como fuentes para el estudio de la práctica musical, nada hay menos ajustado a los criterios históricos que representar una ópera en su integridad y concebida con un criterio de autenticidad basado en la autoridad del compositor sin considerarlo un trabajo colectivo en el que intervenían libretistas, cantantes y toda una serie de convenciones que derivaban en un práctica interpretativa que evita el concepto de fidelidad ${ }^{28}$. Por ese motivo, una lectura demasiado estricta de las modernas ediciones críticas podría conducirla a la ópera a un proceso de "museización" 29 . Un criterio de interpretación "integral" que nunca existió. Justo lo contrario de lo que estos libretos históricos nos explican.

\section{BIBLIOGRAFÍA}

BIANCONI, Lorenzo: “Sillaba, quantità, accento, tono” Il saggiatore musicale, XII, I (Bologna, 2005) pp. 183-218.

BOHIGAS TARRAGÓ, P.: Las compañías dramáticas extranjeras en Barcelona, Barcelona, Diputación Provincial Instituto del Teatro, 1946

FABBRI, Paolo: Metro e canto nell'opera italiana. Torino, EDT, 2007.

GOSSETT, Philip: Divas and scholars. Chicago, Chicago University Press, 2008.

LA VIA, Stefano: Poesia per musica e musica per poesia. Dai trovatori a Paolo Conte, Roma, Carroci, 2006.

PAGÁN, Víctor y VICENTE, Alfonso de: Catálogo de obras de Ramón Carnicer, Madrid, Editorial Alpuerto, 1997.

PORISS, Hilary: Changing the score. Arias Prima donnas and the Authority of Performance. New York, Oxford University Press, 2009.

SUBIRÁ, José: Variadas versiones de libretos operísticos. Madrid, CSIC, 1973

\section{Libretos citados:}

La Gioventú di Enrico V. Barcelona, Tip. Di Giuseppe Torner,1826.

Elisa y Claudio. Madrid, Imprenta de Sancha, 1826

El Tancredo. Madrid, 1829.

28 PORISS, 2007: 4-5

29 A propósito de la interpretación moderna de las ediciones críticas de las óperas italianas Cfr. GOSSETT, 2008. 
Caritea Reina de España, Madrid, Imprenta de Sancha, 1830.

Il conte Ory, Tipografia della vedova e figli di Antonio Brusi, 1830

Bianca di Messina. Madrid, Imprenta de I. Sancha, 1832

L'elisir d'amore. Madrid, Imprenta de I. Sancha, 1833.

L'elisir d'amore. Barcelona, Tipografia Vedova e figli di Antonio Brusi, 1833.

La Sonambula, Imprenta de Sancha, Madrid, 1834.

Moisés en Egipto, Valencia, Imp. De J. Ferrer de Orga, 1842.

Maria Stuarda, Barcelona, Dalla tipografia del Constitucional, 1843.

Linda di Chamounix. Barcelona, Agostino Gaspar e Roca, Barcelona, 1844.

Puritanos y caballeros, Valencia, Giuseppe Ferrer de Orga, 1845.

El trovador, Madrid, Imprenta de D. José Trujillo, 1854.

La Traviata, Barcellona, Tip. de Gaspare e Roca, 1855.

Juan Tenorio o El disoluto castigado, Barcelona, Imprenta de Tomás Gorchs, 1866.

Recibido: 24/04/2012

Aceptado: 21/02/2013 